\title{
Risk factors for the onset and persistence of neck pain in undergraduate students: 1-year prospective cohort study
}

\author{
Siriluck Kanchanomai ${ }^{1}$, Prawit Janwantanakul ${ }^{2 *}$, Praneet Pensri ${ }^{2}$ and Wiroj Jiamjarasrangsi ${ }^{3}$
}

\begin{abstract}
Background: Although neck pain is common in young adulthood, studies on predictive factors for its onset and persistence are scarce. It is therefore important to identify possible risk factors among young adults so as to prevent the development of neck pain later in life.

Methods: A prospective study was carried out in healthy undergraduate students. At baseline, a self-administered questionnaire and standardized physical examination were used to collect data on biopsychosocial factors. At 3, 6, 9 , and 12 months thereafter, follow-up data were collected on the incidence of neck pain. Those who reported neck pain on $\geq 2$ consecutive follow-ups were categorized as having persistent neck pain. Two regression models were built to analyze risk factors for the onset and persistence of neck pain.

Results: Among the recruited sample of 684 students, $46 \%$ reported the onset of neck pain between baseline and 1-year follow-up, of whom 33\% reported persistent neck pain. The onset of neck pain was associated with computer screen position not being level with the eyes and mouse position being self-rated as suitable. Factors that predicted persistence of neck pain were position of the keyboard being too high, use of computer for entertainment $<70 \%$ of total computer usage time, and students being in the second year of their studies.

Conclusion: Neck pain is quite common among undergraduate students. This study found very few proposed risk factors that predicted onset and persistence of neck pain. The future health of undergraduate students deserves consideration. However, there is still much uncertainty about factors leading to neck pain and more research is needed on this topic.
\end{abstract}

\section{Background}

Neck pain is common among adults, affecting $14-71 \%$ of adults at some point in their lives [1]. Its 1-year prevalence in adults ranges at 16-75\% [1]. A substantial 19$37 \%$ proportion of neck pain patients will develop chronic neck pain $[2,3]$. Neck pain causes considerable personal discomfort due to pain, disability, and impaired quality of life, and may affect work. The economic consequences of treating disabling neck pain are significant [4-6]. Bernaard et al [7] recently postulated that the total yearly cost of neck and upper limb symptoms in the Netherlands due to decreased productivity, sick

\footnotetext{
* Correspondence: prawit.j@chula.ac.th

${ }^{2}$ Department of Physical Therapy, Faculty of Allied Health Sciences,

Chulalongkorn University, Bangkok, Thailand

Full list of author information is available at the end of the article
}

leave, chronic disability for work, and medical costs was 2.1 billion Euros.

Adolescents with neck pain are at high risk of having such symptoms in adulthood $[8,9]$. Life-long chronic neck pain may have its origins in childhood [10]. Thus to reduce the prevalence of neck pain in adults, knowledge regarding factors that can predict its onset and persistence in younger population is important [8].

Increasing evidence suggests a high prevalence of musculoskeletal symptoms in the neck and upper extremity among undergraduate students, ranging at $48-78 \%$ $[8,11-13]$. In a Swedish cohort of university students $15 \%$ developed neck or upper back pain during 1-year follow-up [14]. Neck pain is assumed of multi-factorial origin, indicating that individual, physical, and psychosocial factors can contribute to its onset and persistence $[6,15]$. In the general population McLean et al [16]
C Biomed Central

(c) 2011 Kanchanomai et al; licensee BioMed Central Ltd. This is an Open Access article distributed under the terms of the Creative Commons Attribution License (http://creativecommons.org/licenses/by/2.0), which permits unrestricted use, distribution, and reproduction in any medium, provided the original work is properly cited. 
systematically reviewed 14 prospective cohort studies and revealed that female sex, older age, high job demands, low social/work support, ex-smoker, and history of low back and neck disorders were linked to the onset of neck pain. In the working population, Côté et al [5] in their systematic literature review reported that risk factors associated with neck pain included age, previous musculoskeletal pain, high quantitative job demands, low social support at work, job insecurity, low physical capacity, poor computer workstation design and work posture, sedentary work position, repetitive work, and precision work. However, in undergraduate students only cross-sectional studies have been previously conducted on factors associated with neck and upper extremity pain $[11,17,18]$. It is not possible to establish causal relations between exposures and outcome in cross-sectional studies. Research to identify risk factors of neck pain requires longitudinal research design that permits tracking of study participants over time [19].

Computer use is very common among undergraduate students [18] and some epidemiological studies have been published with regard to its relation to onset of neck pain [20-22]. Undergraduate students involved in prolonged computer work and with high numbers of years of computer use more frequently reported upper extremity symptoms $[11,12,23]$. However, little is known about relations between computer use-related factors and onset and persistence of neck pain among undergraduate students.

There is also limited evidence of relations among clinical risk factors and neck pain. Most prior studies investigated the effects of biopsychosocial factors on neck pain in undergraduate students regardless of clinical factors such as muscle strength, endurance, and joint mobility $[11,12,23]$. Clinical factors may be a valuable diagnostic tool for early detection of musculoskeletal disorders [24-26]. Abnormal muscle strength, endurance, and joint mobility may lead to abnormal biomechanics of body movement, causing abnormal physical load to various tissues including muscles, ligaments, and bone. Thus individuals with abnormal muscle strength, endurance, and joint mobility may be susceptible to musculoskeletal injury [27].

The aims of this study were to examine the 1 -year incidence and persistence of neck pain and to explore its biopsychosocial risk factors in undergraduate students.

\section{Methods}

\section{Study Population and Procedures}

A prospective cohort study with 1-year follow-up was conducted. At baseline, a self-administered questionnaire was sent to undergraduate students at Thammasat
University aged 18-25 years. Subjects were excluded if they had reported neck pain in the previous 3 months, had any physician-diagnosed CNS/PNS neurological or musculoskeletal disorders, or history of upper extremity or spinal surgery. Those who were eligible for the study were invited to undergo a laboratory physical examination. The study was approved by Thammasat University Human Ethics Committee.

\section{Questionnaire}

The self-administered questionnaire comprised three sections designed to gather data on individual, computer use-related, and psychosocial factors as well as neck pain.

Individual factors include sex, age (18-20 or $21-25$ years $)$, body mass index $(<18.5, \geq 18.5-<25$, or $\geq 25$ $\mathrm{kg} / \mathrm{m}^{2}$ ), year of study (first to fifth year), chronic diseases (yes or no), field of study (art/humanities or science), and weekly frequency of exercise (regular, occasional, or no exercise).

Computer use-related factors include type of computer (desktop or notebook), years of computer use $(<5$, $5-7,8-9$, or $>9$ years) and average amount of daily computer use $(<3$ or $\geq 3$ hours/day). Respondents were asked whether during computer use their head, upper back, low back, and arms were supported, their feet flat on the floor, and their elbows, hips, knees, and ankles positioned at $90^{\circ}$ flexion (yes or no). The questionnaire asked respondents, based on their own perceptions, to indicate the position of the computer screen (whether the top of the screen was positioned at a level horizontal with the eyes when they sat and looked straight ahead) and the appropriateness of the position of keyboard and mouse during computer use (suitable, too high, or too low). Respondents were asked about the percent time of computer use for study and entertainment as well as percentage duration using keyboard and mouse/touchpad $(<70 \%$ or $\geq 70 \%)$.

Psychosocial factors were assessed by Thai Mental Health Indicator Questionnaire (TMHI-15), a reliably validated instrument [28]. The questionnaire comprises 15 domains that assess general well-being, confidence in coping, kindness and altruism, self-esteem, and supporting factors. Each question is rated on four levels such as 0 , completely disagree; 1 , somewhat disagree; 2 , somewhat agree; 3 , completely agree. Respondents were asked whether the statements applied to them during the preceding 1 month. The total score of the test thus ranged from 0 to 45 . The mental health score was scaled into three groups such as $\leq 27$, worse than normal; 28-34, normal; 35-45, better than normal).

To assess neck pain during the previous 3 months, a picture of the body from the standardized Nordic questionnaire [29] and the question "Have you experienced 
any neck pain lasting $>24$ hours during the past 3 months?" were included in the questionnaire.

\section{Physical examination}

The physical examination was selected based on the hypothetical effect of prolonged computer use on body parts, which may lead to forward head posture, round shoulders and kyphotic upper thoracic spine [30,31]. These changes are likely to decrease neck mobility, neck muscle endurance, and nerve mobility as well as increase muscle tightness [32].

Each participant underwent a physical examination according to standardized protocol and the examiner was blinded to the questionnaire outcomes. Physical examinations included the following items and took a 45-minute single session to complete.

Neck range of motion assessment looked at active range of motion for neck flexion, extension, rotation, and lateral rotation using a Myrin goniometer [33]. In the starting position, each subject looked directly forward with the neck in a neutral position. The subject was then asked to move the head towards each direction as far as possible, and the degree of neck motion in each direction was recorded.

Pectoralis major muscle length was assessed according to guidelines described by Kendell and McCreary [34]. A subject's testing arm was positioned in approximately $135^{\circ}$ shoulder abduction and lateral rotation with the elbow fully extended. The arm was dropped to table level with the low back remaining flat on a table. The examiners recorded the position of the arm relative to table level. To be regarded as normal, the extended arm should drop down to table level.

Neck extensor and flexor endurance were assessed according to the procedures described by Lee [35] and Harris et al [36], respectively. For the neck extensor muscles endurance test, a subject laid prone on a plinth with their head and neck over the edge of the plinth. The subject was instructed to hold the head steady in a position with the chin retracted and the cervical spine horizontal, monitored by a Myrin goniometer placed immediately above the tip of the right ear. The test was discontinued if the subject was not able to hold the position because of fatigue or pain, or if the subject lost $>5^{\circ}$ of upper cervical spine retraction for $>5$ seconds. The examiner recorded the muscle performance in seconds. For the neck flexor muscles endurance test, a subject lay on a plinth. The subject was instructed to lift the head until it was approximately $2.5 \mathrm{~cm}$ above the plinth while keeping the chin retracted to the chest. The test was discontinued if the subject's head touched the plinth for $>1$ second. The examiner recorded the muscle performance in seconds.

Upper limb nerve tension was assessed according to the procedures described by Butler [37]. A subject lay supine on the plinth then the examiner depressed the shoulder girdle followed by abducting the shoulder $110^{\circ}$, flexing the elbow $90^{\circ}$, supinating the forearm, extending both wrist and finger, laterally rotating the shoulder, and extending the elbow. The examiner carefully extended the elbow to the point where the subject began to feel ache, pain, tingling, or discomfort. The range of elbow extension was measured by standard goniometer aligned along the mid-humeral shaft, medial epicondyle, and ulnar styloid.

Tertiles were used for categorizing the outcomes of neck range of motion, neck flexor endurance, and nerve tension tests. The outcome from the neck extensor endurance test had very low variance among the study sample; thus it was scaled into two groups based on mean score (522 seconds). The outcome of the pectoralis major muscle length assessment was classified into two groups: normal or restricted length.

Repeatability of data from the questionnaire and physical examination was assessed in 20 undergraduate students. Each subject was tested on two occasions separated by an interim of 7 days between measurements for the questionnaire and 1 day for the physical examination.

\section{Follow-up}

Subjects were followed every 3 months for 12 months by telephone. The yes/no question "Have you experienced any neck pain lasting $>24$ hours during the past 3 months?" was asked at each follow-up. If they answered "Yes", follow-up questions about the cause of neck pain were asked. Subjects who reported an accident preceding the neck pain episode or physician diagnosis of congenital anomaly of the spine, rheumatoid arthritis, infection of the spine and discs, ankylosing spondylitis, cervical spondylosis, malignant tumor, systemic lupus erythematosus, or osteoporosis were excluded from the study. Those who reported neck pain for $\geq 2$ consecutive follow-ups were categorized as having persistent neck pain.

\section{Statistical analyses}

For the reliability study of questionnaire outcomes, the intraclass correlation coefficient (ICC $[1,1]$ ) was calculated for continuous data and Spearman's rho $(\rho)$ for nominal and ordinal data. ICC $(1,1)$ was calculated for physical examination outcomes.

Subject characteristics were described by means or proportions. Percent missing data in individual, computer use-related, and psychosocial factor categories was $0.1 \%, 1.3 \%$, and $0.2 \%$, respectively. To retain the statistical power of the database, missing data were handled by "hot-deck imputation" procedure. A respondent was selected at random from the total sample of the study 
and the value for that person was assigned to the case in which information was missing. This procedure was conducted repeatedly for each missing value until the dataset was complete [38].

Two regression models were built to analyze risk factors for onset and persistence of neck pain. Initially, univariate analysis was carried out first to determine significant differences in the onset and persistence of neck pain with various biopsychosocial characteristics. Separate multivariable logistic regression models were then performed to assess associations between onset and persistence of neck pain and biopsychosocial factors. Backward selection procedures were used in the statistical modeling. Any factors with p-value $\leq 0.2$ in the univariate analysis were eligible for addition into the modeling procedures. Odds ratios (OR) associated with particular factors were adjusted for the effect of all other factors in the model. Adjusted ORs and $95 \% \mathrm{CI}$ for the final models are presented. Statistical significance was set at the $5 \%$ level. All statistical analyses were performed using SPSS statistical software, version 17.0 (SPSS Inc, Chicago, IL, USA).

\section{Results}

The reliability results demonstrated moderate $(0.60)$ to excellent (1.00) repeatability for questionnaire outcomes and moderate $(0.71)$ to excellent $(0.86)$ for physical examination outcomes.

Among a total of 3545 students who received the questionnaire 2614 responded (response rate, $73.7 \%$ ). Of these, 103 were excluded because they did not meet inclusion criteria, giving an eligible population of 2511 . In total, 684 students agreed to participate in the physical examination. Five hundred twenty-four (77\%) students were followed for 1 year and 160 (23\%) students could not be contacted during the follow-up period. Table 1 presents the demographic characteristics of the study population. A total of 239 (46\%) students reported new onset of neck pain during the follow-up, of whom 79 (33\%) reported persistent neck pain.

\section{Risk factors for neck pain}

According to univariate analyses factors showing p-value $<0.2$ were neck extension range of motion, right upper limb tension outcome, positions of elbows, knees, and ankles during computer use, upper back and elbow support, positions of computer screen, keyboard, and mouse and percent duration of mouse use. Thus these factors were selected for further analysis. Multivariable logistic regression analyses revealed that positions of computer screen and mouse were associated with newonset neck pain (Table 2).

Students reporting that computer screen position was not level with the eyes were at greater risk of developing
Table 1 Characteristics of undergraduate students ( $n=524)$

\begin{tabular}{lcccc}
\hline Characteristic & N & $\%$ & Mean & SD \\
\hline Sex & 138 & 26.3 & & \\
-Male & 386 & 73.7 & & \\
-Female & & & 19.4 & 1.1 \\
Age (years) & & & & \\
Year of study & 183 & 34.9 & & \\
-Year 1 & 247 & 47.1 & & \\
-Year 2 & 91 & 17.4 & & \\
-Year 3 & 0 & 0 & & \\
-Year 4 & 3 & 0.6 & & \\
-Year 5 & & & & \\
Field of study & 175 & 33.4 & & \\
- Arts/humanities & 349 & 66.6 & & \\
- Science/health science & & & 2.9 & 1.8 \\
Hours of daily computer use & & & &
\end{tabular}

neck pain than those reporting that computer screen position was level with the eyes (adjusted OR, 1.64; 95\% CI, 1.13-2.36).

Students reporting that the mouse position was too low were at lower risk of developing neck pain than those reporting mouse position suitable (adjusted OR, 0.52; 95\%CI, 0.28-0.99).

\section{Risk factors for the persistence of neck pain}

According to univariate analyses factors showing p-value $<0.2$ were neck flexor endurance, year of study, percent time of computer use for entertainment, positions of elbows and ankles during computer use, positions of computer screen, keyboard, and mouse. Thus these factors were selected for further analysis. Multivariable logistic regression analyses revealed that year of study, percent time of computer use for entertainment, and positions of keyboard were associated with persistent neck pain (Table 3 ).

Second year students were at significantly higher risk of experiencing persistent neck pain than first year students (adjusted OR, 1.90; 95\%CI, 1.08-3.35).

Students who reported using a computer for entertainment $\geq 70 \%$ were at lower risk of experiencing persistent neck pain compared with whose use was $<70 \%$ (adjusted OR, 0.44; 95\%CI, 0.21-0.95).

Students reporting that keyboard position was too high were at greater risk of experiencing persistent neck pain than those reporting it was suitable (adjusted OR, 2.18; 95\%CI, 1.21-3.91).

\section{Discussion}

The principle aim of the present study was to determine the 1-year incidence and persistence of neck pain among undergraduate students. The 1-year incidence of 
Table 2 Incidence of neck pain and adjusted odds ratio (ORadj) with 95\% confidence intervals (95\%Cl) with respect to factors in the final modeling $(n=524)$

\begin{tabular}{|c|c|c|c|c|c|}
\hline Factors & $\mathbf{N}$ & $\begin{array}{c}\text { Incidence } \\
\text { n (\%) }\end{array}$ & $\mathrm{OR}_{\mathrm{adj}}$ & $95 \% \mathrm{Cl}$ & $P$ \\
\hline \multicolumn{6}{|c|}{ Elbows positioned at $90^{\circ}$ angle } \\
\hline - Yes & 132 & $49(37.1)$ & 1.00 & & \\
\hline - No & 392 & $190(48.5)$ & 1.52 & $0.99-2.31$ & 0.052 \\
\hline \multicolumn{6}{|c|}{ Computer screen is positioned at a level horizontal with the eyes } \\
\hline - Yes & 221 & $85(38.5)$ & 1.00 & & \\
\hline - No & 303 & $154(50.8)$ & 1.64 & $1.13-2.36$ & $0.008^{*}$ \\
\hline \multicolumn{6}{|c|}{ Mouse height } \\
\hline - Suitable & 382 & $172(45)$ & 1.00 & & \\
\hline - Too high & 93 & $50(53.8)$ & 1.30 & $0.82-2.10$ & 0.272 \\
\hline - Too low & 49 & $17(34.7)$ & 0.52 & $0.28-0.99$ & $0.045^{*}$ \\
\hline \multicolumn{6}{|c|}{ Percent duration of mouse use during desktop } \\
\hline$-<70$ & 427 & $201(47.1)$ & 1.00 & & \\
\hline$-\geq 70$ & 97 & $38(39.2)$ & 0.66 & $0.42-1.04$ & 0.075 \\
\hline
\end{tabular}

Significance and $\mathrm{OR}_{\mathrm{adj}}$ with $95 \% \mathrm{Cl}$ from the multivariate analysis

${ }^{*} P \leq 0.05$

neck pain among undergraduate students in this study was high, at $46 \%$ among whom $33 \%$ reported persistent neck pain. Grimby-Ekman et al [14], on the other hand, reported that the annual incidence of neck or upper back pain in Swedish undergraduate students was $15 \%$. The discrepancy between our and previous studies may be due to difference in frequency of data collection during follow-up and the definition of symptomatic case. Grimby-Ekman et al [14] followed their subjects on a yearly basis, whereas in this study subjects were followed every 3 months for $\leq 1$ year. Data collection every 3 months would reduce the influence of recall bias. Also, in the previous study a symptomatic case was defined as an individual who experienced pain for $>7$ days whereas in this study it was $>24$ hours. Consequently, it is likely that a far greater number of subjects were identified as symptomatic cases in this study.

Neck pain is regarded as a chronic episodic condition characterized by persistent, recurrent, or fluctuating pain and disability [3]. Earlier studies showed that persistent musculoskeletal symptoms were common among young population $[8,14,39]$. Slightly more than one quarter of our study sample who reported new onset of neck pain experienced persistent neck pain. In this

Table 3 Rate of persistent neck pain and adjusted odds ratio (ORadj) with $95 \%$ confidence intervals $(95 \% \mathrm{Cl})$ with respect to factors in the final modeling $(n=524)$

\begin{tabular}{|c|c|c|c|c|c|}
\hline Factors & $\mathrm{N}$ & $\begin{array}{l}\text { Persistent rate } \\
\text { n (\%) }\end{array}$ & $\mathrm{OR}_{\mathrm{adj}}$ & $95 \% \mathrm{Cl}$ & $P$ \\
\hline \multicolumn{6}{|c|}{ Year of study } \\
\hline$-1^{\text {st }}$ year & 183 & $21(11.5)$ & 1.00 & & \\
\hline$-2^{\text {nd }}$ year & 247 & $47(19.0)$ & 1.90 & $1.08-3.35$ & $0.027^{*}$ \\
\hline$-3^{\text {rd }}$ year & 91 & $10(11.0)$ & 0.96 & $0.42-2.15$ & 0.912 \\
\hline$-5^{\text {th }}$ year & 3 & $1(33.3)$ & 7.09 & $0.57-87.70$ & 0.127 \\
\hline \multicolumn{6}{|c|}{ Percent time of computer use for entertainment } \\
\hline$-<70$ & 426 & $70(16.4)$ & 1.00 & & \\
\hline$-\geq 70$ & 98 & $7(9.2)$ & 0.44 & $0.21-0.95$ & $0.036^{*}$ \\
\hline \multicolumn{6}{|c|}{ Elbows positioned at $90^{\circ}$ angle } \\
\hline - Yes & 129 & $13(10.1)$ & 1.00 & & \\
\hline - No & 395 & $66(16.7)$ & 1.76 & $0.92-3.35$ & 0.087 \\
\hline \multicolumn{6}{|c|}{ Keyboard height } \\
\hline - Suitable & 370 & $52(14.1)$ & 1.00 & & \\
\hline - Too high & 85 & $22(25.9)$ & 2.18 & $1.21-3.91$ & $0.009^{*}$ \\
\hline - Too low & 69 & $5(7.2)$ & 0.46 & $0.17-1.20$ & 0.113 \\
\hline
\end{tabular}

Significance and $\mathrm{OR}_{\text {adj }}$ with $95 \% \mathrm{Cl}$ from multivariate analysis ${ }^{*} P<0.05$. 
study, persistent neck pain was defined as that reported for $\geq 2$ consecutive follow-ups. There is a lack of consensus over the operational definition of persistent musculoskeletal pain. Stanton et al [40] defined recurrence as persistence of pain reported both at baseline and follow-up assessment with no recovery, whereas Hill et al [41] proposed that persistent pain could reflect chronic, recurrent, or continuous pain. In the present study, we did not ask subjects whether they had experienced any recovery period of pain since they previously reported symptoms. Thus it is not possible to differentiate those who had recurrent pain from those who had continuous pain. However, within this limitation, our findings suggest that students with neck pain may become symptomatic adults, highlighting an urgent need for stakeholders to pay more attention to the problem of neck pain in the young population to reduce the impact of neck pain later in life.

A secondary aim of this study was to identify risk factors for onset and persistence of neck pain. Computer userelated factors contributed significantly to these. However, risk factors for onset differed from those for persistence of neck pain, as was found in previous studies $[8,42]$. Persistent pain can have broad and profound effects on wellbeing with significant impairment of physical and psychological health [43]. Thus information about risk factors for persistent neck pain is of considerable importance.

Onset of neck pain was predicted by the computer screen position not being level with the eyes. High computer screen height results in the neck being more erect [44]; simultaneous increase in muscle activity of the neck extensor and sternocleidomastoid muscle was reported in this posture, and therefore prolonged computer use in this posture may be harmful [45]. The effect of low computer screen is inconclusive. Studies showed that low computer screen height increases neck flexion, neck extensor activities and compressive loading of neck ligaments, joint capsules, and other structures of the cervical spine, thus possibly increasing musculoskeletal strain in the upper body [46-49]. However, Fostervold et al [50] showed that working with low monitor screen height improved oculomotor status with significant reductions in musculoskeletal symptoms in the upper body. In the present study respondents were asked only whether the top of the computer screen was positioned at a level horizontal with the eyes when they sat and looked straight ahead. Further study is required to evaluate the relation between high/low computer screen height and neck pain in undergraduate students.

A mouse position self-rated as too low decreased the risk of onset of neck pain. This finding is contrary to the common concept of "good computer posture" often described as a position in which the upper arm is perpendicular to the floor, the elbow at a right angle, and forearm parallel to the floor [51]. However, Marcus et al
[52] showed that elbow angles between $137^{\circ}$ and $148^{\circ}$ while using the mouse were correlated to lower risk of developing neck and shoulder pain in newly hired computer workers. Although the exact elbow angle while using a mouse was not measured in the present study, it is plausible that mouse position self-reported as too low may correlate with elbow angles $>90^{\circ}$. This hypothesis warrants further investigation.

Factors that predicted persistence of neck pain were students being in the second year of their studies, use of computer for entertainment $<70 \%$ of total computer usage time, and position of the keyboard being too high. The risk of persistent neck pain was 1.9-fold higher for second year students in comparison with first year students. Ndetan et al [53] found that chiropractic students are predominantly exposed to injury risk factors during the first, third, and sixth academic trimesters. However, the finding may not necessarily reflect other student groups. To our knowledge, this study is the first to demonstrate that year of undergraduate study significantly correlated with neck pain. This information may be of importance for developing viable prevention strategies of neck pain in young population. Further study is needed to focus on identifying year of study factors so as better to understand how year of study interacts with persistent neck pain.

A higher percent time of computer use for entertainment reduced the risk of persistent neck symptoms. Computer use for entertainment included activities such as chatting, playing games, listening to music, and watching movies. Hakala et al [54] suggested that the basic mechanism of computer game playing mostly required repetitive hand motion in sitting position and dynamic action where players change postures freely, thereby minimizing loading of the upper extremities. Thus computer use for entertainment may not require the user to be in static postures for prolonged periods. It is also plausible that computer use for entertainment reduces mental stress [55]. Bongers et al [56] suggested that psychosocial demands can exceed an individual's coping capabilities, resulting in a stress response that in turn could produce muscle tension, static loading of muscles, or generate other physiological responses that may result in musculoskeletal symptoms.

A keyboard position self-rated as too high increased the risk of persistent neck pain. Faucett et al [57] found that higher keyboard height (with respect to elbow height) was associated with increased risk of neck, upper back, and upper extremity discomfort. Mekhora et al [58] found that neck and shoulder discomfort significantly declined when keyboard level was adjusted to suit the individual's comfort and proposed that adjustment of keyboard level would reduce the need to reach the hand forward and backward or to elevate the 
shoulder. Therefore, less muscle activity would be present after the adjustment.

Interestingly, no psychosocial and clinical domains remained in the final model. Although it is currently accepted that a large index number within psychosocial dimensions contributes to onset and persistence of musculoskeletal symptoms in adults [59], evidence for such effect in the young population is far from conclusive. Grimby-Ekman et al [14] found that perceived stress was a risk factor for developing neck or upper back pain and for persistent neck or upper back pain in Swedish undergraduate students. On the other hand, Hanvold et al [8] reported no association between stress level and incidence of neck pain during 3-year follow-up among technical school students. In the present study we only examined a selected group of psychosocial and clinical factors. Other important psychosocial and clinical factors may be identified in future work.

The major strength of this study is its prospective design and the evaluation of broad biopsychosocial factors for their contribution to neck pain. However, the study has several weak points. First, the nature of several biopsychosocial factors and the diagnosis of neck pain were subjective, which may have led to inaccuracy. Future studies should consider inclusion of objective information to increase accuracy. Second, information regarding frequency and severity of pain was not collected in this study. Further study should gather this information to enhance understanding regarding relations between risk factors and musculoskeletal symptoms in undergraduate students. Third, subjects in this study were recruited only from one university. Thus generalization of the results to other undergraduate student populations may be limited.

\section{Conclusions}

Among a large sample of undergraduate students 46\% reported neck pain during a 1-year period of follow-up, of whom 33\% experienced persistent neck pain. Very few proposed risk factors were found to predict onset and persistence of neck pain, which included certain aspects related to computer use and year of study. One strategy to prevent morbidity in adults should focus on the health of undergraduate students. An education program should be introduced for undergraduate students regarding how properly to do computer work to avoid neck pain.

\section{Acknowledgements}

This work was funded by the Chulalongkorn University Centenary Academic Development Project - 12, Graduate School, Chulalongkorn University and the National Science and Technology Development Agency.

\section{Author details}

${ }^{1}$ Biomedical Sciences (Interdisciplinary Program) Graduate School,

Chulalongkorn University, Bangkok, Thailand. ²Department of Physical
Therapy, Faculty of Allied Health Sciences, Chulalongkorn University, Bangkok, Thailand. ${ }^{3}$ Department of Preventive and Social Medicine, Faculty of Medicine, Chulalongkorn University, Bangkok, Thailand.

\section{Authors' contributions}

All authors had access to the data. SK provided concept/research design, data collection, data analysis and manuscript writing. PJ provided concept/ research design, data analysis and manuscript writing. PP and WJ provided concept/research design and manuscript writing. All authors read and approved the final manuscript.

\section{Competing interests}

The authors declare that they have no competing interests.

Received: 6 December 2010 Accepted: 15 July 2011

Published: 15 July 2011

\section{References}

1. Fejer R, Kyvik KO, Hartvigsen J: The prevalence of neck pain in the world population: a systematic critical review of the literature. Eur Spine J 2006, 15(6):834-848.

2. Breivik H, Collett B, Ventafridda V, Cohen R, Gallacher D: Survey of chronic pain in Europe: Prevalence, impact on daily life, and treatment. European Journal of Pain 2006, 10(4):287-333.

3. Côté $P$, Cassidy JD, Carroll LJ, Kristman V: The annual incidence and course of neck pain in the general population: a population-based cohort study. Pain 2004, 112(3):267-273.

4. Ariëns GA, Bongers PM, Hoogendoorn WE, van der Wal G, van Mechelen W: High physical and psychosocial load at work and sickness absence due to neck pain. Scand J Work Environ Health 2002, 28(4):222-231.

5. Côté P, van der Velde G, Cassidy JD, Carroll LJ, Hogg-Johnson S, Holm LW, Carragee EJ, Haldeman S, Nordin M, Hurwitz EL, et al: The Burden and Determinants of Neck Pain in Workers: Results of the Bone and Joint Decade 2000-2010 Task Force on Neck Pain and Its Associated Disorders. Journal of Manipulative and Physiological Therapeutics 2009, 32(2, Supplement 1):S70-S86.

6. Hogg-Johnson S, van der Velde G, Carroll L, Holm LW, Cassidy JD, Guzman J, Côté P, Haldeman S, Ammendolia C, Carragee E, et al: The Burden and Determinants of Neck Pain in the General Population: Results of the Bone and Joint Decade 2000-2010 Task Force on Neck Pain and Its Associated Disorders. Journal of Manipulative and Physiological Therapeutics 2009, 32(2, Supplement 1):S46-S60.

7. Bernaards CM, Ariëns GA, Hildebrandt VH: The (cost-)effectiveness of a lifestyle physical activity intervention in addition to a work style intervention on the recovery from neck and upper limb symptoms in computer workers. BMC Musculoskelet Disord 2006, 7:80.

8. Hanvold TN, Veiersted KB, Waersted M: A prospective study of neck, shoulder, and upper back pain among technical school students entering working life. J Adolesc Health 2010, 46(5):488-494.

9. Siivola SM, Levoska S, Latvala K, Hoskio E, Vanharanta H, KeinanenKiukaanniemi S: Predictive factors for neck and shoulder pain: a longitudinal study in young adults. Spine 2004, 29(15):1662-1669.

10. Brattberg G: Do pain problems in young school children persist into early adulthood? A 13-year follow-up. European Journal of Pain 2004, 8(3):187-199.

11. Katz JN, Amick BC, Carroll BB, Hollis C, Fossel AH, Coley CM: Prevalence of upper extremity musculoskeletal disorders in college students. Am J Med 2000, 109(7):586-588.

12. Schlossberg EB, Morrow S, Llosa AE, Mamary E, Dietrich P, Rempel DM: Upper extremity pain and computer use among engineering graduate students. Am J Ind Med 2004, 46(3):297-303.

13. Menéndez CC, Amick BC III, Jenkins M, Caroom C, Robertson M, Harrist RB Katz JN: Upper extremity pain and computer use among engineering graduate students: a replication study. Am J Ind Med 2009, 52(2):113-123.

14. Grimby-Ekman A, Andersson EM, Hagberg M: Analyzing musculoskeletal neck pain, measured as present pain and periods of pain, with three different regression models: a cohort study. BMC Musculoskelet Disord 2009, 10:73.

15. Guzman J, Hurwitz EL, Carroll LJ, Haldeman S, Côté P, Carragee EJ, Peloso PM, van der Velde G, Holm LW, Hogg-Johnson S, et al: A New Conceptual Model of Neck Pain: Linking Onset, Course, and Care: The Bone and Joint Decade 2000-2010 Task Force on Neck Pain and Its 
Associated Disorders. Journal of Manipulative and Physiological Therapeutics 2009, 32(2, Supplement 1):S17-S28.

16. McLean SM, May S, Klaber-Moffett J, Sharp DM, Gardiner E: Risk factors for the onset of non-specific neck pain: a systematic review. J Epidemiol Community Health 2010, 64(7):565-572.

17. Hayes MJ, Smith DR, Cockrell D: Prevalence and correlates of musculoskeletal disorders among Australian dental hygiene students. Int J Dent Hyg 2009, 7(3):176-181.

18. Noack-Cooper KL, Sommerich CM, Mirka GA: College students and computers: assessment of usage patterns and musculoskeletal discomfort. Work 2009, 32(3):285-298.

19. Carroll LJ, Hogg-Johnson S, van der Velde G, Haldeman S, Holm LW Carragee EJ, Hurwitz EL, Côté P, Nordin M, Peloso PM, et al: Course and Prognostic Factors for Neck Pain in the General Population: Results of the Bone and Joint Decade 2000-2010 Task Force on Neck Pain and Its Associated Disorders. Journal of Manipulative and Physiological Therapeutics 2009, 32(2, Supplement 1):S87-S96.

20. Jensen C: Development of neck and hand-wrist symptoms in relation to duration of computer use at work. Scand J Work Environ Health 2003, 29(3):197-205.

21. Eltayeb S, Staal JB, Hassan A, de Bie RA: Work related risk factors for neck, shoulder and arms complaints: a cohort study among Dutch computer office workers. J Occup Rehabil 2009, 19(4):315-322.

22. Tornqvist EW, Hagberg M, Hagman M, Risberg EH, Toomingas A: The influence of working conditions and individual factors on the incidence of neck and upper limb symptoms among professional computer users. Int Arch Occup Environ Health 2009, 82(6):689-702.

23. Chang CH, Amick BC III, Menendez CC, Katz JN, Johnson PW, Robertson M, Dennerlein JT: Daily computer usage correlated with undergraduate students' musculoskeletal symptoms. Am J Ind Med 2007, 50(6):481-488.

24. Zetterberg C, Forsberg A, Hansson E, Johansson $H$, Nielsen P, Danielsson B, Inge G, Olsson B-M: Neck and upper extremity problems in car assembly workers. A comparison of subjective complaints, work satisfaction, physical examination and gender. International Journal of Industrial Ergonomics 1997, 19(4):227-289.

25. Kilbom A: Isometric strength and occupational muscle disorders. Eur Appl Physiol Occup Physiol 1988, 57(3):322-326.

26. Hamberg-van Reenen $\mathrm{HH}$, Ariëns GA, Blatter BM, Twisk JW, van Mechelen W, Bongers PM: Physical capacity in relation to low back, neck, or shoulder pain in a working population. Occup Environ Med 2006, 63(6):371-377.

27. Sander M: Ergonomics and the management of musculoskeletal disorder. 2 edition. St. Louis: Butterworth; 2004

28. Apichai $\mathrm{M}$, Tavee T, Pichet $\mathrm{U}$ : The development and testing of a new Thai Mental Health Indicator (TMHI). J Psychiatr Assoc Thailand 2005, 50:71-91.

29. Kuorinka I, Jonsson B, Kilbom A, Vinterberg H, Biering-SØrensen F, Andersson G, JØrgensen K: Standardised Nordic questionnaires for the analysis of musculoskeletal symptoms. Applied Ergonomics 1987, 18(3):233-237.

30. Wilson A: Effective management of musculoskeletal injury-A clinical ergonomics approach to prevention, treatment and rehabilitation- Edinburgh: Churchill Livingstone; 2002.

31. Ming Z, Närhi M, Siivola J: Neck and shoulder pain related to computer use. Pathophysiology 2004, 11(1):51-56.

32. Norris C: Back stability: integrating science and therapy. 2 edition. Champaign: Human Kindtics; 2008.

33. Clarkson H: Musculoskeletal assessment: Joint range of motion and manual muscle strength. 2 edition. London: Lippincott Williams \& Wilkins; 2000

34. Kendell F, McCreary E, Provance P: Muscle testing and function. 4 edition. Baltimore: William \& Wilkins; 1993.

35. Lee H, Nicholson LL, Adams RD: Neck muscle endurance, self-report, and range of motion data from subjects with treated and untreated neck pain. J Manipulative Physiol Ther 2005, 28(1):25-32.

36. Harris KD, Heer DM, Roy TC, Santos DM, Whitman JM, Wainner RS: Reliability of a measurement of neck flexor muscle endurance. Phys Ther 2005, 85(12):1349-1355.

37. Butler D: Mobilisation of the nervous system Melbourne: Churchill Livingstone; 1992.

38. Aday LA: Designing \& conducting health surveys. 2 edition. San Francisco: Jossey-Bass Publishers; 1996.
39. Ståhl M, Kautiainen H, El-Metwally A, Häkkinen A, Ylinen J, Salminen JJ, Mikkelsson M: Non-specific neck pain in schoolchildren: Prognosis and risk factors for occurrence and persistence. A 4-year follow-up study. Pain 2008, 137(2):316-322.

40. Stanton TR, Latimer J, Maher CG, Hancock M: Definitions of recurrence of an episode of low back pain: a systematic review. Spine 2009, 34(9):E316-322.

41. Hill J, Lewis M, Papageorgiou AC, Dziedzic K, Croft P: Predicting persistent neck pain: a 1-year follow-up of a population cohort. Spine 2004, 29(15):1648-1654.

42. Johnston V, Souvlis T, Jimmieson NL, Jull G: Associations between individual and workplace risk factors for self-reported neck pain and disability among female office workers. Applied Ergonomics 2008, 39(2):171-182.

43. Manchikanti L, Singh V, Datta S, Cohen SP, Hirsch JA: Comprehensive review of epidemiology, scope, and impact of spinal pain. Pain Physician 2009, 12(4):E35-70.

44. Villanueva MB, Jonai H, Sotoyama M, Hisanaga N, Takeuchi Y, Saito S: Sitting posture and neck and shoulder muscle activities at different screen height settings of the visual display terminal. Ind Health 1997, 35(3):330-336.

45. Seghers J, Jochem A, Spaepen A: Posture, muscle activity and muscle fatigue in prolonged VDT work at different screen height settings. Ergonomics 2003, 46(7):714-730.

46. Straker $L$, Jones KJ, Miller J: A comparison of the postures assumed when using laptop computers and desktop computers. Applied Ergonomics 1997, 28(4):263-268.

47. Turville KL, Psihogios JP, Ulmer TR, Mirka GA: The effects of video display terminal height on the operator: a comparison of the 15 degree and 40 degree recommendations. Appl Ergon 1998, 29(4):239-246.

48. Burgess-Limerick R, Plooy A, Fraser K, Ankrum DR: The influence of computer monitor height on head and neck posture. International Journal of Industrial Ergonomics 1999, 23(3):171-179.

49. Szeto GP, Lee R: An ergonomic evaluation comparing desktop, notebook, and subnotebook computers. Arch Phys Med Rehabil 2002, 83(4):527-532.

50. Fostervold Kl, Aarås A, Lie I: Work with visual display units: Long-term health effects of high and downward line-of-sight in ordinary office environments. International Journal of Industrial Ergonomics 2006, 36(4):331-343.

51. Working Safely with Video Display Terminals. [http://www.osha.gov/ Publications/osha3092.pdf].

52. Marcus M, Gerr F, Monteilh C, Ortiz DJ, Gentry E, Cohen S, Edwards A, Ensor C, Kleinbaum D: A prospective study of computer users: II. Postural risk factors for musculoskeletal symptoms and disorders. Am J Ind Med 2002, 41(4):236-249.

53. Ndetan HT, Rupert RL, Bae S, Singh KP: Prevalence of Musculoskeletal Injuries Sustained by Students While Attending a Chiropractic College. Journal of Manipulative and Physiological Therapeutics 2009, 32(2):140-148.

54. Hakala PT, Rimpelä AH, Saarni LA, Salminen JJ: Frequent computer-related activities increase the risk of neck-shoulder and low back pain in adolescents. Eur J Public Health 2006, 16(5):536-541.

55. Leung L: Stressful life events, motives for Internet use, and social support among digital kids. Cyberpsychol Behav 2007, 10(2):204-214.

56. Bongers PM, de Winter CR, Kompier MA, Hildebrandt VH: Psychosocial factors at work and musculoskeletal disease. Scand I Work Environ Health 1993, 19(5):297-312.

57. Faucett J, Rempel D: VDT-related musculoskeletal symptoms: interactions between work posture and psychosocial work factors. Am J Ind Med 1994, 26(5):597-612.

58. Mekhora K, Liston CB, Nanthavanij S, Cole JH: The effect of ergonomic intervention on discomfort in computer users with tension neck syndrome. International Journal of Industrial Ergonomics 2000, 26(3):367-379.

59. Linton SJ: A review of psychological risk factors in back and neck pain. Spine 2000, 25(9):1148-1156.

\section{Pre-publication history}

The pre-publication history for this paper can be accessed here: http://www.biomedcentral.com/1471-2458/11/566/prepub

doi:10.1186/1471-2458-11-566

Cite this article as: Kanchanomai et al:: Risk factors for the onset and persistence of neck pain in undergraduate students: 1-year prospective cohort study. BMC Public Health 2011 11:566. 